\title{
Visual search for simple volumetric shapes
}

\author{
JAMES M. BROWN \\ University of Georgia, Athens, Georgia \\ NAOMI WEISSTEIN \\ State University of New York, Buffalo, New York \\ and \\ JAMES G. MAY \\ University of New Orleans, New Orleans, Louisiana
}

\begin{abstract}
Five experiments measured reaction time (RT) to detect the presence or absence of a simple volumetric shape (target) dependent on the number of display items (distractors) and their depicted three-dimensional (3-D) orientation. Experiments 1-4 examined every pairwise combination of two different simple volumetric shapes in two 3-D orientations. Conditions exhibiting "pop-out" could be predicted by differences in their two-dimensional (2-D) features. Conditions in which search was slower support previously found search asymmetries for particular 2-D features. When the distractors were a mixture of the other shapes in the same 3-D orientation, search was serial, except when the target had a curved principal axis (Experiment 5). The results suggest that these simple volumetric shapes are not processed preattentively.
\end{abstract}

It is known that a number of attributes of the retinal image are processed very early by the visual system, as evidenced by the way they "pop out" in search tasks. When a target is easily distinguished from surrounding distractors by a difference along a single dimension (e.g., color-find a red circle amid green circles), detection time is independent of the number of distractors. When a target pops out automatically and effortlessly from distractors, it is considered to be processed preattentively, without the need for focused attention. Orientation (Julesz \& Bergen, 1983), curvature (Treisman \& Gormican, 1988), closure (Treisman \& Souther, 1985), color (Treisman \& Gelade, 1980), and stereoscopic depth (Nakayama \& Silverman, 1986) are some examples of the attributes, or features, that have been shown to be processed effortlessly and automatically (see Treisman, 1986, for a review). Although the majority of features found to pop out have been related to two-dimensional (2-D) information in the distal stimulus, recent evidence suggests that some three-dimensional (3-D) information can also produce pop-out (e.g., the 3-D orientation of objects [Enns, 1990; Enns \& Rensink, 1990b; Ramachandran \& Plummer, 1989] and the direction of lighting [Enns, 1990; Kleffner \& Ramachandran, 1989]). The fact that these types of 2-D and 3-D information can lead to pop-out suggests that this information is processed very rapidly, in parallel across the visual field. It also suggests that this information is available very early in visual processing.

This work was started while the first author was on an NIH postdoctoral trainee fellowship at the Kresge Hearing Research Laboratory of the South, New Orleans, Louisiana. Reprint requests and all other correspondence should be addressed to James M. Brown, Department of Psychology, University of Georgia, Athens, GA 30602.
Information from early visual processing is used at some point and in some way to help segregate and recognize the various objects from their backgrounds. One recent approach to understanding this complex problem is recognition-by-components ( $R B C$ ) theory (Biederman, 1987). According to RBC theory, objects are processed as a combination of a limited number of simple, volumetric shapes called geons (for geometric ions). An initial edge extraction stage provides information for other stages that parse the object at regions of concavity and detect nonaccidental properties of the objects' edges (e.g., symmetry, collinearity, curvilinearity, parallelism, and types of vertices). This information contributes to the determination of four attributes of the simple volumes making up an object. Three of the attributes are related to the cross section of the simple volumes (curved vs. straight edges, constant vs. expanded vs. expanded and contracted size, and symmetry), and one attribute is related to the shape of their principal axes (straight vs. curved). Potential components (geons) of an object are determined from the output of these stages. The object can then be identified by matching the particular combination of geons with stored representations of objects in memory.

An appealing feature of RBC theory is the idea of geons as the fundamental components of object recognition, analogous to the concept of phonemes as the fundamental components of speech recognition. Having a limited set of components that, in combination, can account for the objects (words) we perceive is very computationally practical. In addition, if a match is not found for an object (word) it can still be described and considered without having to be labeled. Thus, a combination of phonemes may not match a word we can recognize, but we can describe it ("I think he said 'friz-nip,' whatever that 
means"). The explanatory power of geons makes them theoretically appealing as the fundamental components of object recognition but also raises questions about our ability to process them.

The main question addressed here was whether geons are detected automatically and preattentively or whether some attentional processing is required to differentiate one geon from another. In other words, would geons pop out in a visual search task? As Biederman (1987) suggests,

in a given moment of attention, it may be the case that the values of the four attributes of the components are detected as independent features. In the cases where the attributes, taken independently, can define different volumes, as with the shape of cross sections and axes, an act of attention might be required to determine the specific component generating those attributes.... At the other extreme, it may be that an object recognition system has evolved to allow automatic determination of the geons. (p. 25)

According to the fundamental perceptual assumption of RBC theory, components are differentiated on the basis of perceptual attributes in the 2-D image that are readily detectable and relatively independent of viewing position and degradation (Biederman, 1987). This implies that a cylinder (a geon) should be perceived as different from a block (another geon), independent of the position/orientation of the shapes relative to the viewer (as long as there are no accidental alignments of viewpoints and features; Biederman, 1987).

Are these 3-D primitives of RBC theory also primitives in the traditional use of the term, in that they are detected preattentively, in parallel across the visual field (Enns, 1990; Treisman \& Gelade, 1980; Treisman \& Paterson, 1984; Treisman, Sykes, \& Gelade, 1977)? Do these simple volumetric shapes have a special status in early vision (i.e., in the sense that color and motion do), allowing them to be obtained automatically in an image? The following experiments assessed the time required to detect a simple volumetric shape (target) when it was presented either by itself or with varying numbers of other distractor shapes. If geons are primitives in the traditional sense and are processed preattentively, then any shape (e.g., a cylinder) surrounded by another (e.g., a block) should pop out in a search task independent of the number of distractors and their depicted 3-D orientation. On the other hand, if geons do not pop out, or only pop out when they are depicted in different 3-D orientations, then they would not be considered primitives in the traditional sense. The pop-out effect could be attributed to 2-D and/or 3-D orientation differences alone, primitives already shown to be processed automatically.

\section{EXPERIMENTS 1-4}

\section{Method}

Five experiments measured the reaction time (RT) required to detect the presence or absence of a target shape depending on the number, type, and orientation of distractor shapes. The procedure was exactly the same for Experiments $1-4$, with different shape pairs tested in each experiment. The procedure for Experiment 5 was slightly different and will be described separately.

Subjects. Undergraduate students with normal or corrected-tonormal vision participated in each experiment. All were naive to the purpose of the experiment and received Introductory Psychology course credit for their participation. $N=8$ for all experiments.

Stimuli. Five geons (from Biederman, 1987) were created by using a 3-D computer graphics program (DesignCad-3D). Each shape was created with its long axis oriented along the $z$-axis. One view of each geon was with $30^{\circ}$ rotation to the left ( $y$-axis) and $20^{\circ}$ rotation down ( $x$-axis). This was the first version of each geon (i.e., Orientation 1). The reason for the rotation left and down was to eliminate accidental alignments or odd views. For example, a cylinder would appear as a circle if viewed with no $x$-axis and/or $y$-axis rotation. A second version of each geon was created by rotating the first version $90^{\circ}$ about the $y$-axis to a different 3-D orientation (Orientation 2). See Figure 1 for the two versions of each geon. The geons will be referred to by shape (e.g., Block, Curved Block, Wedge, Megaphone, Cylinder) and depicted 3-D orientation (1 or 2 ). The geons were then transferred to an image processing system (Data Translation frame grabber, Model 2862) and displayed on a video monitor (NEC, Model DP2000). A computer controlled stimulus presentation and recorded the subjects' responses, which

\section{STIMULI 3-D ORIENTATION}

1

block

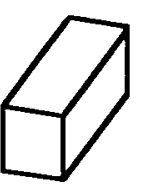

wedge

megaphone

cylinder

\section{curved block}
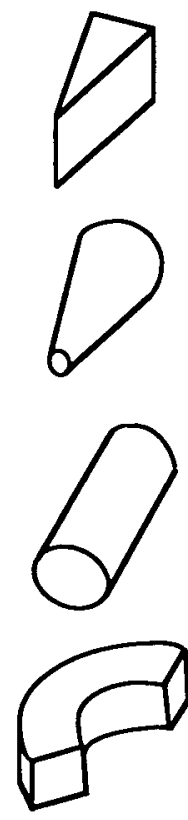

2
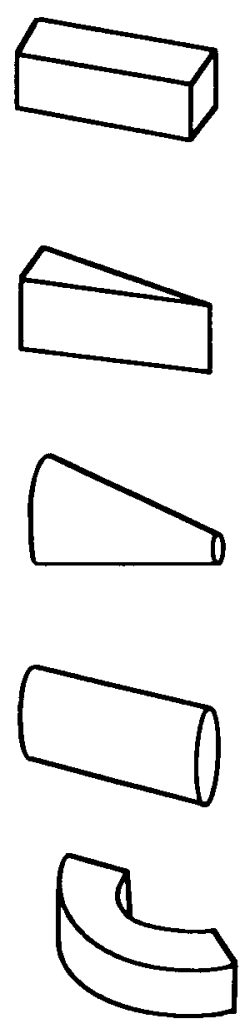

Figure 1. Five simple volumetric shapes depicted in two 3-D orientations. See text for description of experimental comparisons. 
were made by using the computer keyboard. The display area subtended $7.72^{\circ}(\mathrm{h}) \times 8.64^{\circ}(\mathrm{w})$ at a viewing distance of $214 \mathrm{~cm}$. The screen was functionally. divided into a $4 \times 4$ grid. Each geon was randomly shifted $0.32^{\circ}$ up, down, left, or right within a cell in the grid. The height and width of individual shapes varied slightly. Shapes in Orientation 1 were all $1.07^{\circ}$ in height and ranged from $0.70^{\circ}$ to $1.15^{\circ}$ in width. Shapes in Orientation 2 ranged from $0.83^{\circ}$ to $1.07^{\circ}$ in height and from $1.15^{\circ}$ to $1.28^{\circ}$ in width.

Procedure. Each block of trials was preceded by an introduction and 10 practice trials. The introduction showed the subjects which shape was the target and which shape was the distractor for that block of trials. The first practice and experimental trial in each block started with a black fixation point in the middle of a white screen (10 ft). Each stimulus consisted of either 1, 6, or 12 highcontrast black geons on the same white screen, minus the fixation stimulus. The stimulus remained visible until the forced-choice response was made with the left- and right-arrow keys of the computer keyboard. The assignment of these keys to indicate target presence or absence was counterbalanced across subjects in each experiment. Reaction time and accuracy were recorded. The subjects were instructed to indicate, as quickly and accurately as possible, that the target was either present or absent. A plus or minus sign appeared at center screen after each response, indicating a correct and incorrect response, respectively. The plus or minus sign remained on the screen as the fixation stimulus for the next trial. Error rates were less than $8 \%$ for all blocks in all experiments.

During an individual experiment, the subjects saw every combination of two different geons in two 3-D orientations, yielding a total of eight possible target/distractor combinations. ${ }^{1}$ A block of 96 randomized trials consisted of display sizes of 1,6 , and 12 appearing in 32 trials each, 16 with a target present and 16 without a target. The positions of the target and distractors for each trial (or just distractors on target-absent trials) were randomly assigned from the 16 possible grid positions. During a block of trials, the target appeared once for each display size in each of the 16 grid locations. Experiments 1-4 each tested a different pair of geons: Experiment 1-block \& wedge; Experiment 2-cylinder \& megaphone; Experiment 3-megaphone \& wedge; Experiment 4-block \& cylinder.

The eight possible target/distractor combinations for each experiment are listed in Table 1 . The combinations in each table are grouped. The first four combinations compared different geons in different 3-D orientations and were therefore predicted to produce pop-out because of 2-D and 3-D orientation differences. The last four combinations compared different geons in the same 3-D orientation.

The various geon combinations were produced so that when they were in the same 3-D orientation, their 2-D orientation differences were minimized. We predicted that pop-out would not occur in these conditions because there were few, if any, orientation differences. However, if geons are processed automatically, then these conditions would also be expected to produce pop-out, despite the minimized 2-D orientation differences.

Data Analysis. The data analysis was the same for all experiments (1-5). Reaction time data were analyzed by estimating a regression slope as a function of display size $(1,6,12$; Enns \& Rensink, 1990a, 1990b) separately for target-present and target-

Table 1

Summary of Search Data from Experiments 1-4

\begin{tabular}{|c|c|c|c|c|c|c|}
\hline \multirow[b]{2}{*}{ Experiment } & \multirow[b]{2}{*}{ Target } & \multirow[b]{2}{*}{ Distractor } & \multicolumn{2}{|c|}{ Search Rate* } & \multicolumn{2}{|c|}{ Intercept } \\
\hline & & & Present & Absent & Present & Absent \\
\hline \multirow{2}{*}{1} & $\begin{array}{l}\text { Block } 1 \\
\text { Block } 2 \\
\text { Wedge } 1 \\
\text { Wedge } 2\end{array}$ & $\begin{array}{l}\text { Wedge } 2 \\
\text { Wedge } 1 \\
\text { Block } 2 \\
\text { Block } 1\end{array}$ & $\begin{array}{r}3.68 \\
-3.21 \\
2.98 \\
0.09\end{array}$ & $\begin{array}{r}6.09 \\
0.45 \\
-2.97 \\
-0.35\end{array}$ & $\begin{array}{l}554 \\
586 \\
487 \\
539\end{array}$ & $\begin{array}{l}610 \\
608 \\
535 \\
580\end{array}$ \\
\hline & $\begin{array}{l}\text { Block } 1 \\
\text { Block } 2 \\
\text { Wedge } 1 \\
\text { Wedge } 2\end{array}$ & $\begin{array}{l}\text { Wedge } 1 \\
\text { Wedge } 2 \\
\text { Block } 1 \\
\text { Block } 2\end{array}$ & $\begin{array}{c}8.10 \\
23.49 \dagger \\
3.54 \\
8.05\end{array}$ & $\begin{array}{c}16.65 \\
36.58 \dagger \\
6.28 \\
12.09\end{array}$ & $\begin{array}{l}570 \\
565 \\
532 \\
514\end{array}$ & $\begin{array}{l}580 \\
631 \\
561 \\
559\end{array}$ \\
\hline \multirow{2}{*}{2} & $\begin{array}{l}\text { Cylinder } 1 \\
\text { Cylinder } 2 \\
\text { Megaphone } 1 \\
\text { Megaphone } 2\end{array}$ & $\begin{array}{l}\text { Megaphone } 2 \\
\text { Megaphone } 1 \\
\text { Cylinder } 2 \\
\text { Cylinder } 1\end{array}$ & $\begin{array}{r}0.59 \\
-2.74 \\
-2.17 \\
-2.85\end{array}$ & $\begin{array}{r}-3.91 \\
0.86 \\
-4.69 \\
-6.99\end{array}$ & $\begin{array}{l}520 \\
564 \\
530 \\
538\end{array}$ & $\begin{array}{l}584 \\
603 \\
600 \\
609\end{array}$ \\
\hline & $\begin{array}{l}\text { Cylinder } 1 \\
\text { Cylinder } 2 \\
\text { Megaphone } 1 \\
\text { Megaphone } 2\end{array}$ & $\begin{array}{l}\text { Megaphone } 1 \\
\text { Megaphone } 2 \\
\text { Cylinder } 1 \\
\text { Cylinder } 2\end{array}$ & $\begin{array}{c}10.27 \dagger \\
5.09 \\
0.52 \\
0.14\end{array}$ & $\begin{array}{c}13.08 \dagger \\
1.86 \\
3.01 \\
2.78\end{array}$ & $\begin{array}{l}553 \\
556 \\
539 \\
521\end{array}$ & $\begin{array}{l}641 \\
649 \\
611 \\
575\end{array}$ \\
\hline \multirow{2}{*}{3} & $\begin{array}{l}\text { Megaphone } 1 \\
\text { Megaphone } 2 \\
\text { Wedge } 1 \\
\text { Wedge } 2\end{array}$ & $\begin{array}{l}\text { Wedge } 2 \\
\text { Wedge } 1 \\
\text { Megaphone } 2 \\
\text { Megaphone } 1\end{array}$ & $\begin{array}{r}-0.18 \\
0.49 \\
1.28 \\
1.48\end{array}$ & $\begin{array}{l}-2.88 \\
-2.58 \\
-0.16 \\
-0.85\end{array}$ & $\begin{array}{l}556 \\
576 \\
539 \\
527\end{array}$ & $\begin{array}{l}633 \\
636 \\
591 \\
594\end{array}$ \\
\hline & $\begin{array}{l}\text { Megaphone } 1 \\
\text { Megaphone } 2 \\
\text { Wedge } 1 \\
\text { Wedge } 2\end{array}$ & $\begin{array}{l}\text { Wedge } 1 \\
\text { Wedge } 2 \\
\text { Megaphone } 1 \\
\text { Megaphone } 2\end{array}$ & $\begin{array}{c}1.82 \\
11.02 \dagger \\
4.97 \\
2.70\end{array}$ & $\begin{array}{c}5.57 \\
27.45 \dagger \\
3.51 \\
9.01\end{array}$ & $\begin{array}{l}579 \\
584 \\
538 \\
606\end{array}$ & $\begin{array}{l}621 \\
664 \\
623 \\
661\end{array}$ \\
\hline \multirow{2}{*}{4} & $\begin{array}{l}\text { Block } 1 \\
\text { Block } 2 \\
\text { Cylinder } 1 \\
\text { Cylinder } 2\end{array}$ & $\begin{array}{l}\text { Cylinder } 2 \\
\text { Cylinder } 1 \\
\text { Block } 2 \\
\text { Block } 1\end{array}$ & $\begin{array}{r}2.59 \\
-3.85 \\
2.27 \\
0.28\end{array}$ & $\begin{array}{r}3.36 \\
-1.75 \\
-4.08 \\
1.77\end{array}$ & $\begin{array}{l}606 \\
618 \\
567 \\
619\end{array}$ & $\begin{array}{l}700 \\
650 \\
660 \\
703\end{array}$ \\
\hline & $\begin{array}{l}\text { Block 1 } \\
\text { Block } 2 \\
\text { Cylinder } 1 \\
\text { Cylinder } 2\end{array}$ & $\begin{array}{l}\text { Cylinder } 1 \\
\text { Cylinder } 2 \\
\text { Block } 1 \\
\text { Block } 2\end{array}$ & $\begin{array}{c}2.91 \\
6.41 \\
2.93 \\
11.89 \dagger\end{array}$ & $\begin{array}{c}5.57 \\
13.25 \\
6.05 \\
41.64 \dagger\end{array}$ & $\begin{array}{l}609 \\
583 \\
578 \\
679\end{array}$ & $\begin{array}{l}680 \\
648 \\
661 \\
765\end{array}$ \\
\hline
\end{tabular}

\footnotetext{
${ }^{*}$ In milliseconds per item. † Indicates the search rate was significantly different from all others.
} 
absent trials for each subject for each target/distractor combination. Target-present and -absent slopes were then used in separate one-way repeated measures analyses of variance (ANOVAs) to de termine if there were any significant differences in slope (i.e., search rate) between the eight target/distractor combinations. Intercepts were submitted to a similar analysis.

Different criteria have been used to define whether or not the search rate for a target indicates pop-out or preattentive processing. This criterion might be interpreted as a transitional point on a continuum from preattentive processing to processing requiring increasing amounts of attention. Below this criterion, search is considered to be accomplished preattentively. Near this criterion, attention may begin to be required to accomplish the search. Finally, the farther a slope is above this criterion, the greater the likelihood the search was not accomplished preattentively and required increasing amounts of attentional processing to complete. Some studies have designated search rates less than 5 or $6 \mathrm{msec}(\mathrm{Ju}, 1990$; Treisman \& Souther, 1985) as the criterion for pop-out, whereas other studies have designated rates less than $10 \mathrm{msec}$ (Enns \& Rensink, 1990a; Treisman \& Gormican, 1988). One can be fairly confident search is accomplished preattentively by using a criterion slope of $10 \mathrm{msec}$ or less per item to indicate pop-out (i.e., parallel search) for target-present trials (Ju, 1990; Treisman \& Souther, 1985) and to indicate parallel rejection on target-absent trials (Ju, 1990). For target-present and -absent slopes greater than $10 \mathrm{msec}$, a presentto-absent ratio nearer 0.5 than 1.0 was interpreted as suggesting a serial-exhaustive search (Ju, 1990; Treisman and Souther, 1985). Our criterion to decide whether search had been accomplished preattentively or had required some attentional processing was threefold. First, both the target-present and -absent search rates had to be greater than $10 \mathrm{msec}$ for a particular combination. Second, both the target-present and -absent rates had to be significantly different from at least one other condition in the experiment. If these two conditions were met, a separate analysis of that combination was performed. The effect of number of display items and target presence or absence on search rate was assessed in a 3 (number of display items $=1,6,12) \times 2$ (target present/absent) repeated measures ANOVA. Significant main effects for both factors were considered further evidence that search was not accomplished preattentively and some attentional processing was required.

\section{Results}

Experiment 1. There was a significant effect of target/ distractor combinations for both target-present $[F(7,49)=$ $12.93, p<.00001]$ and target-absent slopes $[F(7,49)=$ $6.30, p<.00001]$ and target-present $[F(7,49)=2.58$, $p<.02]$ and -absent intercepts $[F(7,49)=2.24, p<.04$; see Table 1]. Post hoc analysis (Newman-Keuls) revealed that the Block 2/Wedge 2 target-present and -absent slopes were significantly greater than all other target-present and -absent slopes, respectively. The Block1/Wedgel and Wedge $2 /$ Block 2 target-present rates were significantly greater than those in the Block2/Wedge l condition. Separate analyses of the Block2/Wedge 2 combination showed significant main effects for both number of display items $[F(2,14)=16.17, p<.0002]$ and target presence/absence $[F(1,7)=12.42, p<.009]$.

Experiment 2. There was a significant effect of target/ distractor combinations for both target-present $[F(7,49)=$ $10.41, p<.00001]$ and target-absent $[F(7,49)=6.63$, $p<.00001]$ slopes but not for intercepts (see Table 1). Post hoc analysis showed that the Cylinder 1/Megaphone1 target-present and -absent slopes were significantly greater than all other target-present and -absent slopes, respec- tively. A separate analysis of the Cylinder 1/Megaphone 1 condition also showed significant main effects for the number of display items $[F(2,14)=18.26, p<.0001]$ and target presence/absence $[F(1,7)=23.14, p<.001]$.

Experiment 3. There was a significant effect of target/ distractor combinations for both target-present $[F(7,49)$ $=2.87, p<.01]$ and target-absent slopes $[F(7,49)=$ $7.84, p<.00001]$ but not for intercepts (see Table 1). Post hoc analysis showed that the Megaphone 2/Wedge 2 target-present and -absent slopes were significantly greater than all other target-present and -absent slopes, respectively. A separate analysis of the Megaphone2/Wedge 2 condition also showed significant main effects for the number of display items $[F(2,14)=10.41, p<.001]$ and target presence/absence $[F(1,7)=20.78, p<.002]$.

Experiment 4. There was a significant effect of target/ distractor combinations for both target-present $[F(7,49)$ $=5.40, p<.0001]$ and target-absent slopes $[F(7,49)=$ $12.97, p<.00001]$ and target-present $[F(7,49)=3.22$, $p<.007]$ and target-absent intercepts $[F(7,49)=2.33$, $p<.03$; see Table 1]. Post hoc analysis showed that the Cylinder 2/Block2 target-present and -absent slopes were significantly greater than all other present and absent slopes, respectively. The Block2/Cylinder 2 target-present slope was greater than the Block2/Cylinderl target-present slope, and the Block2/Cylinder2 target-absent slope was greater than that in the Cylinder1/Block 2 condition. Separate analyses of the Cylinder $2 /$ Block 2 condition showed significant main effects for the number of display items $[F(2,14)=25.95, p<.00001]$ and for target presence/absence $[F(1,7)=40.70, p<.0004]$.

\section{Discussion}

The results from the four experiments taken as a whole strongly suggest that 2-D featural differences lead to popout in most conditions. Finding there were conditions that did not lead to pop-out also indicates that geons as a whole are not processed automatically and preattentively by the visual system. The four conditions in each experiment comparing different geons in different 3-D orientations exhibited pop-out, as predicted. The results from the four conditions in each experiment comparing different geons in the same 3-D orientation were not, however, as predicted. The differences across experiments for these conditions require separate discussion of their results.

In Experiment 1, the Block2/Wedge2 (23.49-msec targetpresent and 36.58-msec target-absent slopes) condition did not pop out according to the criterion adopted. This condition also produced a present/absent slope ratio of 0.64 , suggesting a self-terminating search. Although both the Block1/Wedge 1 and Wedge1/Block1 conditions led to popout according to our criterion, the faster search in the Wedge1/Block1 condition compared with the slower search in the Block1/Wedgel condition supports previously found search asymmetries in which search for a pair of parallel lines among pairs of converging lines is more difficult than the reverse (Treisman \& Gormican, 1988). The converging lines denoting the principal axis of Wedge 1 may have made it easier to find among Block1 
distractors, in which parallel lines made up the principal axis. A similar logic may also account for the difference between the Block2/Wedge 2 and Wedge $2 / B l o c k 2$ conditions. Their close similarity in 2-D features may be why search was slower in these conditions and why the parallel lines of Block2 were considerably more difficult to discern from the converging lines of Wedge 2 distractors than vice versa.

An interpretation of the results of Experiment 2 is not as straightforward as the other experiments but may be possible by closer examination of the particular 2-D featural differences in each comparison. At first glance, we might attribute the fact that the megaphone always led to pop-out from cylinders in the same 3-D orientation to the asymmetry that search for a pair of converging lines among pairs of parallel lines is faster than search for the opposite (Treisman \& Gormican, 1988). Given this, the cylinders would not be expected to pop out from the megaphones when in the same 3-D orientation. However, this was not the case. Although the Cylinder1/Megaphone1 condition (10.27-msec target-present and 13.08-msec target-absent slopes) was significantly slower according to our criterion, the Cylinder 2/Megaphone 2 condition did produce pop-out. The small difference between targetpresent and -absent slopes for the Cylinder 1/Megaphone1 condition (i.e., a present-to-absent ratio of .79) suggests that the search was not serial exhaustive and that it was almost as easy to decide the target was absent as it was to decide it was present. Closer examination of the differences in 2-D features between Cylinder 2 and Megaphone 2 suggests that different features may have been used, depending on which one was the target, and that these particular features could have led to pop-out of Cylinder 2 . Although the top line denoting the principal axis of Megaphone 2 is a tilted line (such as the parallel tilted lines of Cylinder 2), the bottom line of Megaphone 2 is actually a horizontal line. Searching for Megaphone 2 among Cylinder 2 may have been accomplished by searching for the single feature "horizontal line" among tilted lines instead of searching for a pair of converging lines among pairs of parallel lines. Likewise, search for Cylinder 2 could have been accomplished by searching for the single feature "pair of tilted lines,"' making it relatively easy. This particular featural difference was not present in the Cylinder1/Megaphone1 comparison, and thus the relatively slower search may have been due to searching for a pair of parallel lines among pairs of converging lines.

In Experiment 3, all but the Megaphone2/Wedge 2 condition resulted in pop-out (11.02-msec target-present and 27.45-msec target-absent slopes, present-to-absent ratio of 0.4). Two factors may have contributed to the slower search in this condition compared with the others. First, the close similarity in 2-D features between these shapes in the depicted 3-D orientation would have contributed to the greater difficulty in discriminating them. The second factor may be related to the finding that search for the absence of a feature is more difficult than search for the presence of it (Treisman \& Souther, 1985). The long axis of Megaphone 2 is defined by two lines, whereas three lines define the long axis of Wedge 2 . With their close similarity overall, searching for the absence of the third line was more difficult than searching for its presence. Unlike Megaphonel among Wedgel distractors, in which the circular end of the megaphone could have been a diagnostic feature, the end of Megaphone 2 was not as distinctive.

In the same 3-D orientation conditions of Experiment 4, all but the Cylinder 2/Block 2 (11.89-msec target-present and 41.64-msec target-absent slopes) condition led to popout. Although Cylinder 2 did not pop out from Block2 according to our criterion, searching for Block2 among Cylinder 2 was relatively easier. The difference in search rate between these two conditions may be related to the block's having three parallel lines and the cylinder's having two. Again, this supports the hypothesis that search for the absence of a feature (in our case, a third parallel line) is longer than search for its presence (Treisman \& Souther, 1985). Although this 2-D featural distinction was also true for the Cylinder1/Block1 and Block1/Cylinder1 conditions, their most discriminating features were probably the ends of their shapes (i.e., square vs. circle), making each one equally easy to find among the other.

\section{EXPERIMENT 5}

For an additional test of the perceptibility of these simple volumetric shapes, a final experiment was conducted requiring observers to search for the presence or absence of a target shape when the distractors were a mixture of the remaining shapes, all of which were in the same 3-D orientation.

\section{Procedure}

The subjects searched for a specific target shape in a specific 3-D orientation in separate blocks of trials. The particular targets are listed in Table 2. As before, a block consisted of 96 randomized trials with 1,6 , or 12 geons appearing in 32 trials each, 16 with a target and 16 without a target. The positions of the target and distractors for each trial (or just distractors on target-absent trials) were randomly assigned from the 16 possible grid positions and randomly shifted $0.32^{\circ}$ up, down, left, or right. Distractors were made up of a combination of the four other shapes in the same 3-D orientation. For display size 1, target-absent trials, the distractor was randomly selected from the set of four possible distractors.

Table 2

Summary of Search Data from Experiment 5

\begin{tabular}{lccccc}
\hline & \multicolumn{2}{c}{ Search } & Rate* & & \multicolumn{2}{c}{ Intercept } \\
\cline { 2 - 3 } \cline { 5 - 6 } \multicolumn{1}{c}{ Target } & Present & Absent & & Present & Absent \\
\hline Block 1 & 26.49 & 75.40 & & 535 & 552 \\
Block 2 & 38.88 & 92.74 & & 580 & 602 \\
Cylinder 1 & 22.51 & 54.69 & & 571 & 634 \\
Cylinder 2 & 46.01 & 69.71 & & 722 & 751 \\
Wedge 1 & 38.68 & 88.75 & & 556 & 604 \\
Wedge 2 & 55.61 & 110.37 & & 586 & 620 \\
Curved Block 1 & 7.95 & 14.66 & & 507 & 571 \\
Curved Block 2 & 7.95 & 21.26 & & 549 & 599 \\
Megaphone 1 & 26.98 & 62.50 & & 562 & 593 \\
Megaphone 2 & 38.79 & 94.15 & 637 & 658 \\
\hline
\end{tabular}

*In milliseconds per item. 
For display size 6, target-present trials, each distractor was presented once, and one was randomly chosen to be presented twice. For display size 6, target-absent trials, each distractor was presented once, and two were randomly chosen to be presented twice. For display size 12, target-present trials, each distractor was presented twice, and three were randomly chosen to be presented three times. For display size 12, target-absent trials, each distractor was presented three times. Before each block, the subjects saw a brief introduction showing them the target for that block of trials, followed by 10 practice trials.

\section{Results and Discussion}

There was a significant effect of target/distractor combinations for both target-present $[F(9,63)=19.10, p<$ $.00001]$ and target-absent slopes $[F(9,63)=13.51, p<$ $.00001]$ and target-present $[F(9,63)=3.61, p<.001]$ and target-absent $[F(9,63)=3.24, p<.002]$ intercepts. Post hoc analysis (Newman-Keuls) showed that the Cylinder 2 target-present and -absent intercepts were significantly greater than those in all other conditions. The Curved Block1 and Curved Block2 target-present and -absent slopes were significantly smaller than all other targetpresent and -absent slopes, respectively, except with respect to each other. These two conditions were also the only ones that led to pop-out ${ }^{2}$ (see Table 2 ).

The curved block was the only shape to produce popout from the remaining shapes serving as distractors. The curved lines designating its curved principal axis were obviously a very salient 2-D feature that distinguished it from all other volumetric shapes. The remaining shapes, lacking such a distinguishing feature, had to be searched for serially.

\section{GENERAL DISCUSSION}

The main question addressed by these experiments was whether simple volumetric shapes are detected automatically and preattentively or whether some attentional processing is required to differentiate one shape from another. From the results of Experiments 1-5, we can draw the following general conclusions:

1. Volumetric shapes depicted in different 3-D orientations had such dissimilar 2-D features (e.g., basic image edges) that they always popped out from each other.

2 . Visual search for the simple volumetric shapes tested appears to have been based on 2-D featural differences. Although 3-D orientation may have contributed to the differences in search times found, the relative contribution of 2-D and 3-D orientation differences cannot be determined from these results.

3. The conditions that indicated serial search always had shapes in the same 3-D orientation-that is, conditions in which the shapes were intentionally created to minimize 2-D orientation differences. In some comparisons, search asymmetries for 2-D features were found (e.g., converging vs. parallel lines and feature presence vs. absence), which is consistent with previous search-asymmetry findings.

4 . The only volumetric shape tested with a curved principal axis (e.g., curved block) always popped out from straight-axis distractors (Experiment 5) and vice versa (see
Note 2). This was probably due to the salience of the 2-D featural differences between the straight versus curved lines delimiting the principal axes of the shapes.

Related search experiments (Ju, 1990) conducted at the same time as those described above support these conclusions. Ju tested various pairs of geons while varying distractor 2-D orientation (i.e., rotation in the image plane). In multiple distractor displays, individual distractors were randomly assigned an orientation from four values $\left(30^{\circ}, 120^{\circ}, 210^{\circ}, \& 300^{\circ}\right)$ rotated clockwise from vertical. From her investigations, Ju concluded that

the attentional processing of geons could be predicted from the lines that composed the geons. Thus, there was no need to posit special geon detectors. That is, no qualitative differences occurred between geons and lines that could not be handled by the effects of the lines that composed the geons. (p. 73)

The combined results of our investigations and Ju's (1990) show that geons are not processed by parallel, independent pathways during early visual processing and that some attentional processing is required to differentiate one geon from another.

Considering that some attentional processing seems to be required to differentiate one geon from another, what else can be said about the processing of these simple volumetric shapes? One issue to consider is the difference in search performance for the same geons in Experiment 5 compared with Experiments 1-4. For example, Wedge 1 popped out in Experiments 1 and 3 but was difficult to find in Experiment 5. Aside from demonstrating that geons are not processed by specialized detectors in early visual processing (e.g., as motion and color are), the differences in search performance emphasize how the ability to process a target is affected by the context in which it appears. The number of shared 2-D features between the target and distractors was greater with the heterogeneous distractors in Experiment 5 than with the homogeneous distractors in Experiments 1-4 (i.e., in which the distractors for any block of trials were all the same shape). Thus, with respect to the number of shared 2-D features, search performance decreased both with an increased similarity of targets to nontargets and with a decreased similarity between nontargets (Duncan \& Humphreys, 1989).

If spatial context contributed to the differences in detectability of the same volumetric shape when it was presented in Experiment 5, compared with Experiments 1-4, would detectability be the same if the contexts were eliminated? To examine this possibility, separate analyses were done using target-present, display size 1 trials only and comparing RT for a particular shape when it was the target in Experiment 5 and in other experiments in which the distractors had been in the same 3-D orientation. This resulted in eight analyses with three conditions per analysis: one from Experiment 5 and one each from two other experiments. ${ }^{3}$ Of the eight analyses, only two showed any significant differences in RT across the three conditions compared. Wedge 2 detection was faster in Experiment 1 $(518 \mathrm{msec})$ than in Experiments $3(609 \mathrm{msec}, p<.01)$ 
and 5 (613 msec, $p<.02$ ); Megaphone 2 detection was faster in Experiment 2 (514 msec) than in Experiment 5 (572 msec, $p<\div 05$ ). Geñeral conclusions from these analyses are that (1) the ability to detect a particular shape by itself was fairly consistent across experiments and (2) differences in search performance found for a particular shape comparing Experiment 5 and Experiments 1-4 were caused by the spatial context in which the target was being presented. Remove the context and, for the most part, differences in detection time for a particular geon were eliminated.

Considering that detection time for a particular volumetric shape was fairly consistent across experiments when the spatial context was removed, what can be said about the relative detectability of the different shapes in the different 3-D orientations tested if the spatial context is removed? This question raises two issues. First, was there any difference in the ability to detect the shapes when they were presented by themselves? Second, although 2-D featural differences and similarities would appear to account for the differences in search performance across experiments, was there any influence of 3-D orientation? The visual system is particularly sensitive to things moving in depth directly at it (Regan, Beverly, \& Cynader, 1979), so potential impact and avoidance calculations and decisions can be made. Evolutionarily, this makes sense. Following a similar logic, the visual system might be more sensitive to stationary things pointed or directed toward it, compared with things pointing away because of the potential survival value. Although the principal axes of shapes in Orientation 1 were not pointed in depth directly at the viewer, they were pointed relatively more directly at the viewer than they were in Orientation 2 , in which they pointed sideways and off to the right. Given this logic, it was hypothesized that overall, shapes presented in Orientation 1 would be reacted to faster than in Orientation 2.

To examine the issue of relative detectability and to test the orientation hypothesis, the data of Experiment 5 were used in two additional analyses. ${ }^{4}$ The first analysis tested for differences in target-present search rate dependent on target shape and 3-D orientation. A 5 (target shape) $\times$ 2 (3-D orientation) repeated measures ANOVA revealed both significant main effects of target shape $[F(4,28)=$ $26.13, p<.00001]$ and orientation $[F(1,7)=22.40$, $p<.002]$ and a significant shape $\times$ orientation interaction $[F(4,28)=4.38, p<.007]$. The main effect of target shape was already known from the results of Experiment 5-that is, the curved block always popping out when it was a target. The significant interaction is also due to this fact. The main effect of orientation indicates that overall (i.e., except for the curved block), the search rate was faster when the same shape was in Orientation 1 (mean search rate $=24.52 \pm 3.9 \mathrm{msec}$ ) than when it was in Orientation 2 (mean search rate $=37.45 \pm 6.3 \mathrm{msec}$; see Figure 2).

Using search rate as the dependent measure, however, does not remove the influences of spatial context. The second analysis used RT from target-present, display size 1 trials only, in a 5 (target shape) $\times 2$ (3-D orientation) repeated measures ANOVA. There was a significant main effect of 3-D orientation $[F(1,7)=14.04, p<.007]$, but

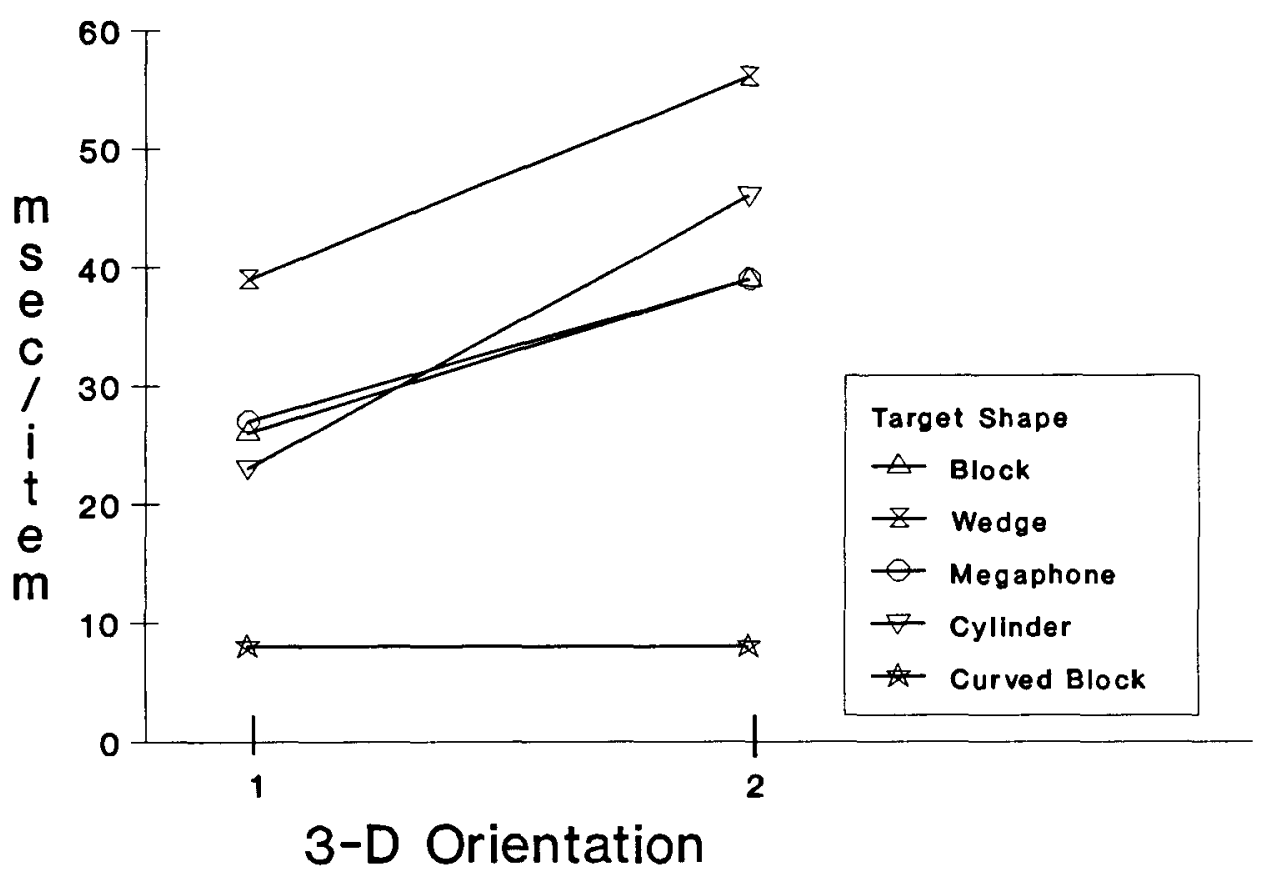

Figure 2. Search rate as a function of target shape and 3-D orientation (data from Experiment 5). 


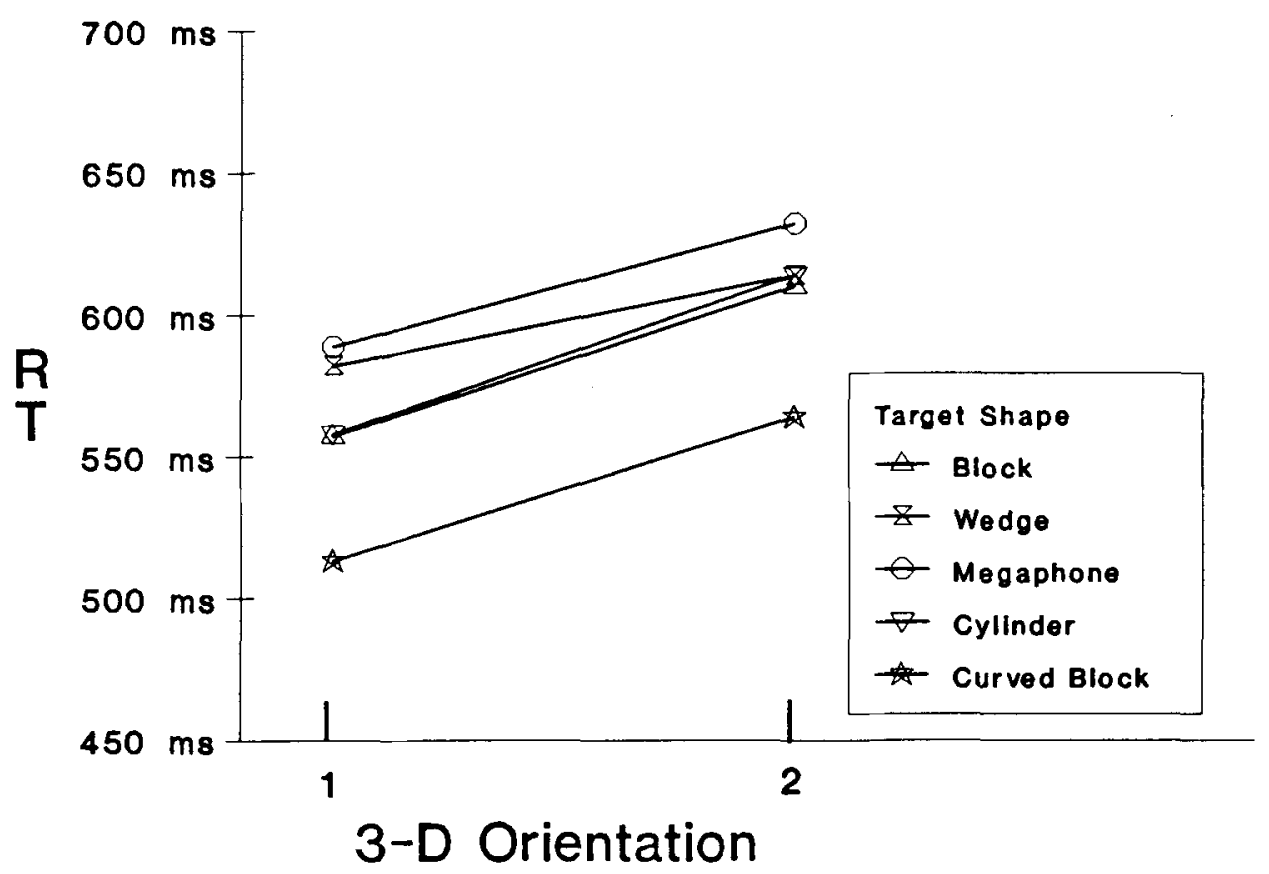

Figure 3. Reaction time to detect a target as a function of target shape and 3-D orientation. Data are from Experiment 5, with the use of display size 1, target-present-only trials.

there was neither a main effect of shape $(p>.08)$ nor a shape $x$ orientation interaction (see Figure 3).

The results of this analysis are informative for two reasons. First, they suggest these volumetric shapes are equally detectable when they are presented by themselves. Second, 3-D orientation information appears to have contributed to the results of Experiment 5 (and, therefore, possibly to Experiments 1-4). All the shapes were detected faster when they were presented in Orientation 1 (mean RT $=559 \pm 10.49 \mathrm{msec}$ ) than when they were presented in Orientation 2 (mean RT $=606 \pm 8.95 \mathrm{msec}$ ) with the spatial context removed. Although our stimuli and experiments were not originally designed to address the issues of relative shape detectability and 3-D orientation influences, the data are strongly suggestive.

Finally, the results of Experiments 1-5 and the additional analyses above support and would, in part, be predicted by a recent neural network implementation of RBC (Hummel \& Biederman, in press). According to this model, geons should fail to pop out because they require temporal resources to bind their constituent features. As features are extracted from an image, they are bound together by a temporal synchronization of their processing. This temporal binding should be accomplished faster when there are fewer extraneous or distracting features in the image (i.e., when the shape is presented by itself). As the similarity of constituent features between a target shape and distractor shapes increases, increasing atten- tional processing is required to suppress potential accidental temporal binding of inappropriate features (Hummel \& Biederman, 1991, in press). According to the model, individual geons are processed as independent combinations of contrastive (qualitative) and metric (quantitative) properties. Thus, if only the properties designating the presence of a particular geon are available in an image, the detectability of that geon should be no different from the detectability of another geon in another image when only the properties designating its presence are available. The lack of a main effect of shape in the last analysis would support drawing such a conclusion from the Hummel and Biederman (in press) model. How the model would account for both the main effect of orientation in the last analysis and studies showing preattentive processing of the 3-D orientation of simple shapes (Enns \& Rensink, $1990 \mathrm{a}, 1990 \mathrm{~b}$ ) is unclear at this time.

In conclusion, five experiments were run to assess whether simple volumetric shapes (geons) are processed preattentively or whether some attentional processing is required. The results indicate that, as a whole, the shapes we tested were not processed preattentively. However, when the target shape had a 2-D feature that was distinctive from the shape(s) of the distractor(s), search could be accomplished preattentively. Additional analyses suggested that there was no difference in RT to the volumetric shapes when they were presented by themselves. Finally, the results of the last experiment also suggest that RT to 
these volumetric shapes was influenced by their depicted 3-D orientation.

\section{REFERENCES}

Biederman, I. (1987). Recognition-by-components: A theory of human image understanding. Psychological Review, 94, 115-147.

Duncan, J., Humphreys, G. W. (1989). Visual search and stimulus similarity. Psychological Review, 96, 433-458.

ENNS, J. T. (1990). Three-dimensional features that pop out in visual search. In D. Brogan (Ed.), Visual search (pp. 37-45). New York: Taylor \& Francis.

ENNS, J. T., \& RENSINK, R. A. (1990a). Influence of scene-based properties on visual search. Science, 247, 721-723.

ENNs, J. T., \& Rensink, R. A. (1990b). Sensitivity to three-dimensional orientation in visual search. Psychological Science, 1, 323-326.

Hummel, J. E., \& Biederman, I. (1991). Binding by phase locked neural activity: Implications for a theory of visual attention. Investigative Ophthalmology \& Visual Science, 32, 716.

Hummel, J. E., \& Biederman, I. (in press). Dynamic binding in a neural network for shape recognition. Psychological Review.

Ju, G. (1990). The role of attention in object recognition: The attentional costs of processing contrasts of non-accidental properties. Unpublished doctoral dissertation, State University of New York at Buffalo.

Julesz, B., Bergen, J. R. (1983). Textons, the fundamental elements in preattentive vision and perception of textures. The Bell System Technical Journal, 62, 1619-1645.

KlefFner, D., \& Ramachandran, V. S. (1989, May). Perception of three-dimensional shape-from-shading. Poster presented at the meeting of the Association for Research in Vision and Ophthalmology, Sarasota, FL.

Nakayama, K., \& Silverman, G. H. (1986). Serial and parallel processing of visual feature conjunctions. Nature, 320, 264-265.

Ramachandran, V. S., \& Plummer, D. J. (1989, May). Preattentive perception of 3-D versus 2-D image features. Paper presented at the meeting of the Association for Research in Vision and Ophthalmology, Sarasota, FL.

Regan, D., Beverly, K., \& Cynader, M. (1979). The visual perception of motion in depth. Scientific American, 241, 136-151.
Treisman, A., \&elade, G. (1980). A feature integration theory of attention. Cognitive Psychology, 12, 97-136.

Treisman, A., \& GoRMICAN, S. (1988). Feature analysis in early vision: Evidence from search asymmetries. Psychological Review, 95, $15-48$.

Treisman, A., \& Paterson, R. (1984). Emergent features, attention, and object perception. Journal of Experimental Psychology: Human Perception \& Performance, 10, 12-31.

Treisman, A., \& Souther, J. (1985). Search asymmetry: A diagnostic for preattentive processing of separable features. Journal of Experimental Psychology: General, 114, 285-310.

Treisman, A., Sykes, M., * Gelade, G. (1977). Selective attention and stimulus integration. In $S$. Dornic (Ed.), Attention and performance (Vol. 6, pp. 333-361). Hillsdale, NJ: Erlbaum.

\section{NOTES}

1. Pilot work comparing the same geon in a different 3-D orientation always led to pop-out. Therefore, such comparisons were not included in these experiments.

2. An additional experiment was run using the combination of the curved block and block with exactly the same procedure, etc. as Experiments 1-4. The results showed pop-out for all comparisons (e.g., block from curved block and vice versa).

3. The eight analyses compared the following conditions from the following experiments. The first condition listed is from Experiment 5, the other two from the experiments noted in ( ).

Block1-Block1/Wedge $1^{(1)}$-Block1/Cylinder $1^{(4)}$

Block 2-Block 2/Wedge 2(1) -Block 2/Cylinder $2^{(4)}$

Cylinder 1-Cylinder1/Block $1^{(4)}$-Cylinder1/Megaphone $1^{(2)}$

Cylinder 2-Cylinder 2/Block 2(4) Cylinder 2/Megaphone 2(2)

Wedge 1-Wedge 1/Block1 ${ }^{(1)}$-Wedge1/Megaphone ${ }^{(3)}$

Wedge 2-Wedge 2/Block $2^{(1)}$-Wedge 2/Megaphone $2^{(3)}$

Megaphone1-Megaphone1/Cylinder $1^{(2)}$-Megaphone1/Wedge $1^{(3)}$

Megaphone 2-Megaphone 2/Cylinder 2(2) -Megaphone 2/Wedge $2^{(3)}$

4. Experiment 5 was used exclusively because only the subjects in this experiment had to detect all the shapes as targets.

(Manuscript received December 18, 1989; revision accepted for publication August 9, 1991.) 